\title{
Central conduction time following surgery for cerebral aneurysm
}

\author{
JOHN E FOX, BERNARD WILLIAMS \\ From the Midland Centre for Neurosurgery and Neurology, Smethwick, Warley, West Midlands, UK
}

SUMMARY Somatosensory evoked potentials have been recorded serially in 21 patients following aneurysm surgery. Central conduction time correlated reasonably well within the patient's clinical state at the time of testing, but it did not act as a useful predictor of clinical deterioration.

Following aneurysm surgery, there is a risk of cerebral ischaemia and infarction. If the ischaemia can be detected at an early stage, it is possible that treatment may prevent the subsequent development of an infarct. ${ }^{12}$ Since it has been shown that central conduction time ${ }^{3}$ is prolonged in cerebral ischaemia, ${ }^{4}$ there has been interest in using this technique to monitor patients' condition following aneurysm surgery. It has been suggested ${ }^{5}$ that a prolonged central conduction time may give evidence of cerebral ischaemia and impending infarction, prior to the development of clinical signs. In the present investigation, central conduction time has been repeatedly measured in patients who have undergone aneurysm surgery in an attempt to correlate variations in latency with the development of neurological complications.

\section{Patients and methods}

Twenty one patients (16 female and five male) were included in this study; the mean age was 40 years (range = 14-57). All had been admitted for surgical treatment of cerebral aneurysm, 19 following a subarachnoid haemorrhage and two after developing symptoms attributable to pressure from the aneurysm. Angiography showed that the site of the aneurysm was on the internal carotid artery in 10 cases, middle cerebral artery in six cases, anterior communicating artery in four cases, carotid bifurcation in two cases, posterior communicating artery in one case and

Address for reprint requests: Dr JE Fox, Dept of Clinical Neurophysiology, Midland Centre for Neurosurgery \& Neurology, Holly Lane, Smethwick, Warley, West Midlands B67 7JX, UK.

Received 9 September 1983 and in revised form 4 February 1984. Accepted 18 February 1984 anterior cerebral artery in one case. Three patients had aneurysms at more than one site. Apart from a IIIrd nerve palsy, clinical examination revealed no neurological abnormality in 18 of the patients. Three patients had a hemiparesis before operation.

Evoked potentials were recorded using surface electrodes placed over the cervical cord and the somatosensory area of the cortex contralateral to the stimulated side; the reference electrode was placed at Fz. Central conduction time was measured using the technique described by Hume and Cant, ${ }^{3}$ the latency of the $\overline{\mathrm{N} 14}$ (cervical) response was subtracted from the latency of the $\overline{\mathrm{N} 20}$ (cortical) response following the presentation of 128 stimuli to the median nerve at the wrist. In addition to an assessment prior to surgery, central conduction time was measured at times which were as close as was practicable to $1,6,12$ or 18,24 , $36,48,72,96$ and 144 hours after operation. Central conduction time was also measured in six normal volunteers; mean age was 35 years (range $=20-62$ ). In order to assess response variability, each subject was tested on seven occasions; the intervals between successive measurements ranged from 6-72 hours, all investigations being completed within a 6 day period.

\section{Results}

\section{NORMAL SUBJECTS}

In the six normal subjects, mean central conduction time was $5.3 \mathrm{~ms}(\mathrm{SD}=0.3 \mathrm{~ms})$. In each individual, central conduction time showed some variation with repeat testing; the maximum difference from each individual's mean central conduction time ranged from $0 \cdot 1-0 \cdot 7 \mathrm{~ms}($ mean $=0.38 \mathrm{~ms})$.

\section{PATIENTS WITHOUT A DEFICIT PREOPERATIVELY}

In the 18 patients with no neurological abnormalities (other than IIIrd nerve palsy) the mean cen- 
Table Changes in central conduction time (CCT) in those patients who developed neurological deficits following surgery

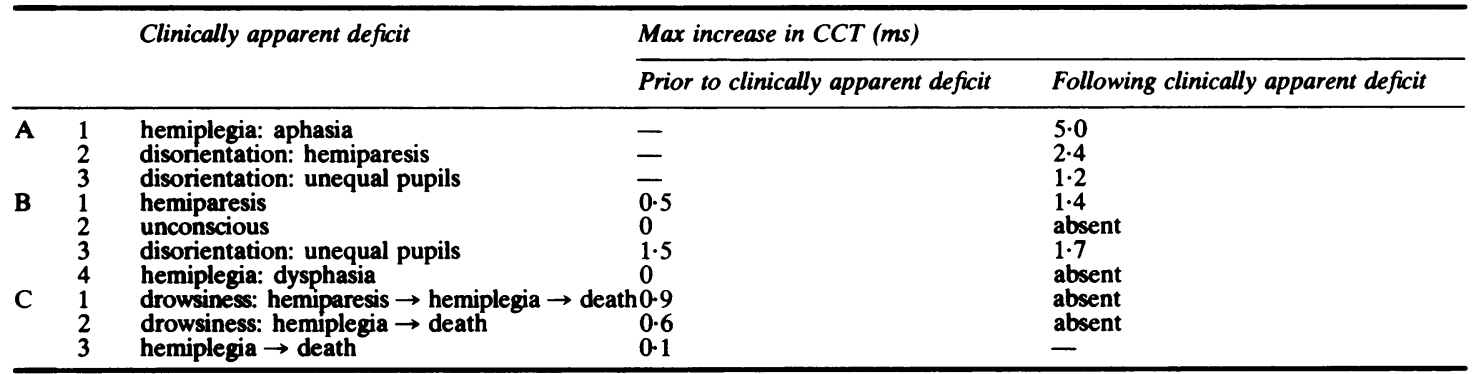

The three patients in group $A$ all had transient neurological abnormalities which were clinically apparent on their return from the operating theatre. The four patients in group B developed neurological abnormalities 4-50 hours following operation: in patients B1-B3, the abnormalities were transient; patient B4 developed a permanent hemiplegia. The three patients in group C developed neurological abnormalities 38-100 hours following their return from theatre: all three patients later died.

-indicates those situations in which CCT could not be measured, either because there was no interval between surgery and the appearance of the deficit $(\mathrm{A1}, 2,3)$ or because of a short interval between the development of hemiplegia and death (C3).

tral conduction time preoperatively was $5.8 \mathrm{~ms}(\mathrm{SD}$ $=0.5 \mathrm{~ms}$ ). After operation, eight patients made an uneventful recovery. Despite the absence of clinical signs, central conduction time was frequently increased compared with the preoperative level: the mean maximum increase was $0.45 \mathrm{~ms}$ (range $=$ $0 \cdot 1-1 \cdot 0 \mathrm{~ms})$. Seven patients developed neurological abnormalities from which they later recovered (six totally and one partially).

The abnormality was clinically apparent immediately after surgery in three of these patients (A1-3 in table) and central conduction time was delayed in all three patients. The clinical state subsequently improved and all three patients were discharged without neurological deficit; central conduction time returned to the preoperative level as the clinical signs abated. In four patients (B1-4), the deficits became clinically apparent after an interval of $4-50$ hours. Prior to the development of clinical signs, only one of these patients showed an increase in central conduction time exceeding $1 \mathrm{~ms}$ (B3). Following the development of the abnormality, however, central conduction time was prolonged or the cortical response was absent in all of the patients. Three of these four patients subsequently made a complete clinical recovery with a concomitant return of central conduction time to the preoperative level. One patient (B4) showed some clinical improvement, but was left with a permanent severe hemiparesis. His cortical somatosensory evoked potential was undetectable when the clinical signs were most severe, but returned as his clinical state improved.

Three patients ( $\mathrm{C} 1-3$ in table) became hemiplegic and later died. The hemiplegia became apparent 38-100 hours after surgery. Prior to the onset of clinically apparent abnormalities, none showed increases in central conduction time greater than 1 ms (see fig). Following the development of the hemiplegia, the cortical somatosensory potential

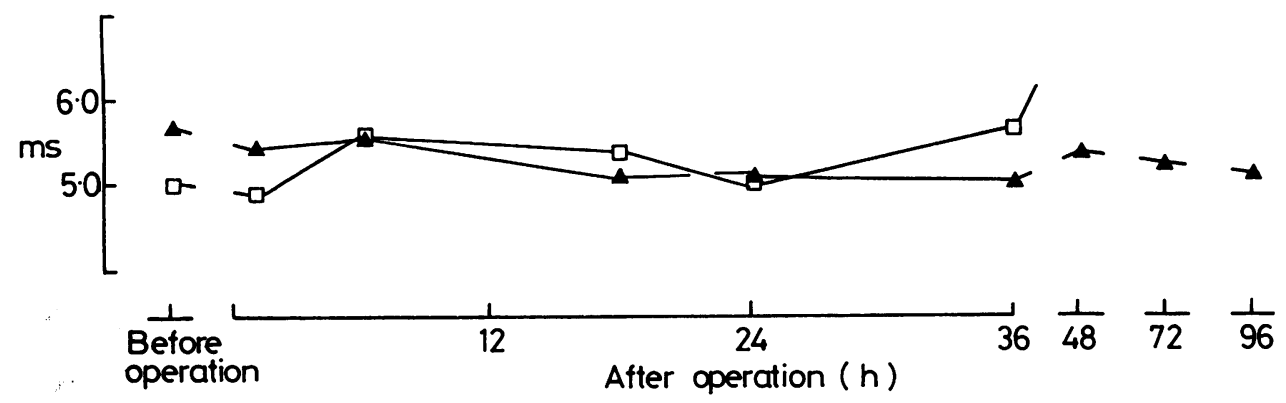

Fig Central conduction time in a patient who developed a hemiplegia and later died (C2). $\square$ shows central conduction time on the operated side and $\mathbf{\Delta}$ on the non-operated side. In the first 36 hours following surgery, the patient showed no significant neurological deficit and there was no significant prolongation of the central conduction time. 38 hours after operation, she developed a hemiparesis, her conscious level deteriorated and she died 5 days after operation. 
was absent in two patients (the third patient died before further central conduction time estimations could be made).

In patients who developed clearly lateralised clinical signs, the maximum increase in central conduction time was invariably seen on the clinically affected side. In four of these patients, a smaller increase was also seen on the opposite side; in one patient (A1), the increase was $2.0 \mathrm{~ms}$, but in the other three the increases were all less than $1 \mathrm{~ms}$. One patient (B2) became unconscious and showed no lateralising signs; central conduction time in this patient was delayed and the cortical potential later became temporarily undetectable on both sides.

\section{PATIENTS WITH A DEFICIT PREOPERATIVELY}

Three patients had a hemiparesis prior to surgery. In two, the central conduction time was delayed and in one, the cortical somatosensory potential was absent on the appropriate side. After operation none of these three patients developed any further deficit and the central conduction time measurements were unchanged from the preoperative state.

\section{Conclusion}

Patients who made a clinically uneventful recovery frequently showed small increases in central conduction time. Much of this could be accounted for by random fluctuation about the mean conduction time, but it is also likely that in some cases it may have resulted from minor degrees of transient ischaemia which are apparently without clinical significance. ${ }^{45}$

In those patients who developed clinical problems, there was frequently an abnormality in central conduction time and the degree of abnormality corresponded reasonably well with the extent of the clinically apparent abnormality. This observation accords with the work of others ${ }^{4-7}$ and suggests that central conduction time may be a helpful way of monitoring changes in patients condition. In the present group of patients, however, a change in central conduction time did not act as a useful predictor of ischaemia or infarction.

We thank Mrs G Linley and the other technicians in the Clinical Neurophysiology Department for their skilful assistance in this project. We also thank the Wellcome Trust for financial support.

\section{References}

' Kosnik EJ, Hunt WE. Post operative hypertension in the management of patients with intracranial aneurysms. $J$ Neurosurg 1976;45: 148-54.

${ }^{2}$ Hope DT, Branston NM, Symon L. Restoration of neurological function with induced hypertension in acute experimental cerebral ischaemia. Acta Neurol Scand 1977;56 suppl 64 27.10-27.11.

${ }^{3}$ Hume AL, Cant BR. Conduction time in central somatosensory pathways in man. Electroencephalogr Clin Neurophysiol 1978;45:361-75.

${ }^{4}$ Branston NM, Symon L, Crockard HA, Pasztor E. Relationship between the cortical evoked potential and local cortical blood flow following acute middle cerebral artery occlusion in the baboon. Exp Neurol 1974; 45: 195-208.

s Symon L, Hargadine J, Zawirski M, Branston N. Central conduction time as an index of ischaemia in subarachnoid haemorrhage. J Neurol Sci 1979;44:95-103.

- Moorthy SS, Markland ON, Dilley RS, McCammon RL, Warren $\mathrm{CH}$. Somatosensory evoked responses during carotid endarterectomy. Anesth Analg 1982;61:87983.

7 Jakubowski J, Bell BA, Symon L, Zawirski MB, Francis DM. A primate model of subarachnoid haemorrhage: change in regional cerebral blood flow, autoregulation carbon dioxide reactivity and central conduction time. Stroke 1982;13:601-11. 